\title{
Establishment and Analysis of Spatiotemporal Variation Hydrological Model of Distributed Rainfall and Evaporation in Biliu River Basin
}

\author{
Qi Liu $\mathbb{D}^{1},{ }^{1,2}$ Xiaolong Zhao $\mathbb{D}^{3},{ }^{3}$ Hongyan Wang, ${ }^{3}$ and Yongfeng Sun ${ }^{3}$ \\ ${ }^{1}$ Shenyang Agriculture University, College of Land and Environment, Shenyang 110866, Liaoning, China \\ ${ }^{2}$ Liaoning Agricultural College, Yingkou 115009, Liaoning, China \\ ${ }^{3}$ Yingkou Hydrologic Bureau of Liaoning Province, Yingkou 115003, Liaoning, China
}

Correspondence should be addressed to Qi Liu; lq19720605@126.com

Received 18 November 2020; Revised 17 December 2020; Accepted 4 January 2021; Published 19 January 2021

Academic Editor: Wei Wang

Copyright (c) 2021 Qi Liu et al. This is an open access article distributed under the Creative Commons Attribution License, which permits unrestricted use, distribution, and reproduction in any medium, provided the original work is properly cited.

\begin{abstract}
The Biliu River originates from the southern foot of Qinling Mountain in Gaizhou city, with an elevation of $1047 \mathrm{~m}$, and is the largest river in Dalian. The hydrological elements mainly include rainfall, runoff, temperature, evaporation, and other time series associated with the hydrological cycle. Among them, runoff is the most visible output performance, and the direct source of runoff is during rainfall. This paper establishes a reservoir scheduling model that considers the influence of multiple uncertainty factors and analyzes the influence of mixed uncertainty on reservoir scheduling and Xingli's objectives based on probability box theory. In terms of uncertainties, the uncertainty of hydrological model parameters and the randomness of precipitation processes are mainly considered, with the former having an impact on river runoff simulation and the latter having an impact on both river runoff simulation and crop irrigation water demand. In the case of the Jing River basin, for example, the results show that, compared to the stochasticity of the precipitation process, the variation in precipitation has a significant effect on irrigation water demand in maize, followed by the frequency of precipitation, and the interaction between the two is not significant.
\end{abstract}

\section{Introduction}

With the rapid socioeconomic development and the influence of changing environment, the contradiction between supply and demand of water resources in the Yellow River basin is becoming more and more acute, and, under the background of uncertainty research, it is of great practical significance to identify the changing characteristics of hydrological processes in river basins and carry out research on water resources regulation and control in order to cope with climate change, explore the sustainable use of water resources in the new era, and improve the efficiency of water resource utilization [1]. Security and the virtuous cycle of hydrological and water resource systems are also of great scientific importance [2]. In the past century, global climate change has been dramatic; meanwhile, human activities such as large-scale water conservation projects and rapid urbanization have changed the subsurface conditions of hydrological processes and the speed of water circulation, and the mechanism of water circulation has undergone significant changes [3]. As a result, a series of water problems, such as water shortage, frequent floods, and droughts, have caused significant negative impacts on the socioeconomic development and ecological health of river basins (regions), especially in developing countries, according to relevant studies [4-7]. In-depth understanding of the characteristics of hydrological process changes is important for better assessment of the hydrological impacts of climate change, water resources simulation and prediction, integrated water resources management, flood prevention and mitigation, etc. [8]. In general, the identification of hydrological process changes is of great importance [9]. Broadly speaking, hydrological process change identification studies can be divided into two main areas: (i) identification 
of hydrological process changes on medium- and long-time scales (years and months) and (ii) studies of extreme hydrometeorological (e.g., extreme rainfall and floods) changes [10].

It is important to note that the different hydrometeorological elements of the hydrological cycle do not occur in isolation but interact with each other [11]. Taking the three basic elements of the hydrological cycle, rainfall, evaporation, and runoff, as an example, runoff is produced by the combined effects of rainfall, evaporation, subsurface, and soil in a watershed; rainfall provides water for processes such as evaporation and is the main source of river runoff in a rain-fed watershed [12]; evaporation, in turn, provides the impetus for rainfall and so on. In a changing environment, the correlation between hydrological and meteorological elements is constantly changing, and it is often difficult to diagnose the variability of a single hydrometeorological element to fully describe the complex nonlinear feedback structure between hydrometeorological variables [13]. How to diagnose the inherent change law of hydrometeorological element dependency and the variation of its correlation is a scientific problem that needs to be solved urgently [14]. At this stage, relatively little research has been done in this area. In rainfall-based watersheds, floods are usually caused by extreme precipitation. What is the variation of the extreme precipitation-flood dependency under changing conditions? It is one of the issues that need attention at this stage [15-18]. The main problem is that the selection of the extreme precipitation-flood dependence variable point is highly subjective, and the different locations of the variable points often have a significant impact on the research results as shown in Figure 1. In a typical snowmelt model, the canopy process could be simulated by the influence of the groundwater, net rain, temperature, and also many other issues. In the SWAT perspective, parameter sensitivity analysis helps to deepen the understanding of the effects of different parameters acting individually or together on the model simulation results and is an important direction and essential link in the field of hydrological modeling research. On the other hand, the study of the risk of extreme rainfall, flooding, and other events in the river basin is of great practical importance for the design of hydraulic engineering and flood prevention [19]. To date, this research has received extensive attention worldwide [20].

Traditional flood risk analysis studies have concluded that the larger the flood, the greater the economic and environmental losses caused by the flood [21]. Therefore, the probability that the peak flood flow of the river exceeds the design value of the downstream flood control project is often the focus of the flood control management department [22]. However, in addition to its "disaster" properties, floods also have certain "resource" properties, such as sand flushing, pollution, replenishment of reservoirs, and groundwater. At this time, higher flood flow/flood flow/flood control project design value is often the focus of flood control management departments. In this case, higher flood flow/volume means more benefits and vice versa [23]. In the case of river sand flushing, for example, a harmonious water-sediment relationship is necessary to maintain a healthy river channel, especially in the sandy region of the Yellow River, which is the study area. During floods, river flow increases and the silt is resuspended and transported downstream [24]. If the river flow is too low during a flood, the silt is difficult to be suspended, which will lead to sediment accumulation, which will cause the river gradient to fall and the river bed to rise, resulting in the phenomenon of overhanging river, threatening the regional flood control safety. Therefore, for sandy areas, it is equally important to clarify the probability of flooding not exceeding the river sediment transport flow during flood season as it is to calculate the probability of flooding exceeding the design value of flood control projects. So far, there is a lack of research on this aspect of the problem. The common methods of parametric sensitivity analysis are local analysis and global analysis. The advantage of global sensitivity analysis is that it cannot only fully consider the effects of different factors on the model output, but also quantify the effects of the interaction between factors on the model output. Nowadays, sensitivity analysis methods based on variance decomposition, such as Sobol method and FAST method, are the hotspots of research in the field of sensitivity analysis. However, it is noteworthy that the above methods are all based on the assumption that the input variables are independent of each other and uncorrelated. In practice, it is often difficult to observe the dependence between the model parameters, so how to conduct parametric sensitivity analysis when the input variables are correlated is the main problem to be explored nowadays. In addition to the above-mentioned parametric uncertainty research, the uncertainty of the model's own structure is also worth focusing on.

Traditional studies have been conducted under the assumption that extreme rainfall and flooding in watersheds are smoothly changing processes, ignoring the fact that the mechanism of stormwater flooding changes with the external environment, especially in areas where human activities have a strong influence. In addition, the influence of human activities such as afforestation, grass planting, and terrace construction on the conversion mechanism of stormwater floods will exist for a long period of time, so it is of great practical and theoretical significance to study the risk of extreme rainfall and flooding events under the premise of considering the influence of the changing environment, so as to provide more practical risk information on regional flood risk assessment and flood management. The Biliu River originates from the southern foot of Qinling Mountain in Gaizhou city, with an elevation of $1047 \mathrm{~m}$, and is the largest river in Dalian. The paper establishes a reservoir planning model that takes into account the impact of several uncertainties and analyses the impact of mixed uncertainties on the reservoir planning and the objectives of Xingli on the basis of probability cost theory. The uncertainty shall take into account in particular the uncertainty of the hydroponic model parameters and the randomness of precipitation processes, the former influencing the flow simulations and the latter influencing both the flow simulations and the water requirements for irrigation of plants. In the case of the Jin river basin, for example, the results show that precipitation fluctuations have a significant impact on the water demand 


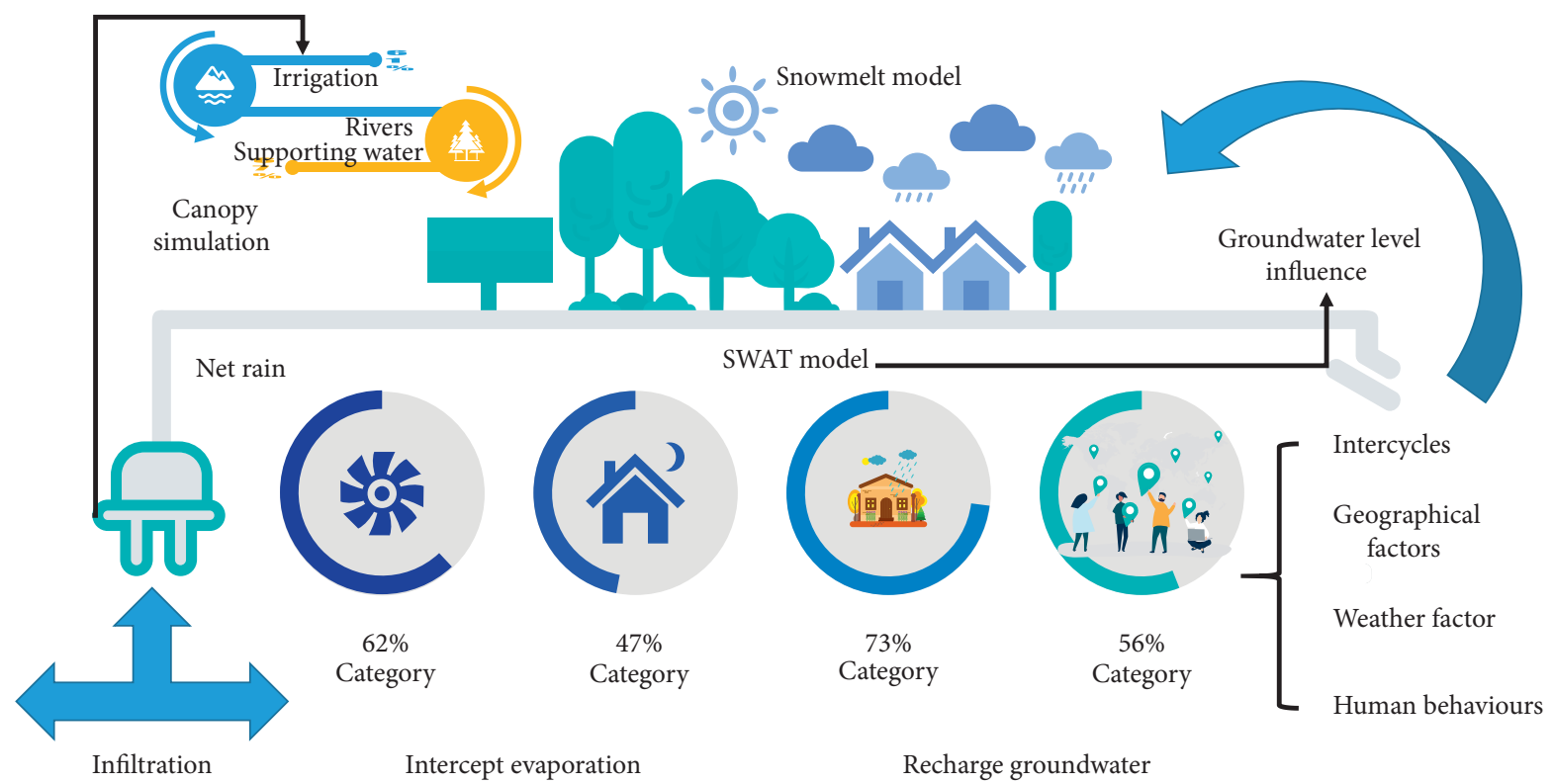

FIGURE 1: Different methods for studying rainfall and temporal and spatial variability of rivers.

for maize irrigation, followed by an increased precipitation volume compared to the probability of precipitation processes. The interaction between the two is not important.

\section{Basin Profile of the Study Area}

2.1. Basin Overview. The Biliu River originates from the southern foot of Qinling Mountain in Gaizhou city, with an elevation of $1047 \mathrm{~m}$ above sea level. The river enters Zhuanghe city of Dalian, Liaoning. It flows through Guiyunhua, Hehua Mountain, Chengshan, and Mingyang in Zhuanghe city and 8 townships and towns such as Anbo, Shuangta, Mopan, and Chengzitan in Pulandian city and is filled into the Yellow Sea at Xietun in Chengzitan town. Biliuhe is located at longitude $122^{\circ} 17^{\prime}-122^{\circ} 54^{\prime}$ east, latitude $39^{\circ} 33^{\prime}-40^{\circ} 21^{\prime}$ north, in the eastern side of the rest of the Thousand Mountains. The total length of the main stream of Biliuhe is $156 \mathrm{~km}$, and the length of the main stream in Dalian is $100 \mathrm{~km} .55 \mathrm{~km}$ away from the mouth of Biliuhe, there is a reservoir of Biliuhe, which is the most important water source in Dalian. It is a large reservoir with a maximum storage capacity of 934 million $\mathrm{m}^{3}$, mainly used for urban water supply, but also for flood control, power generation, fish farming, tourism, and other comprehensive benefits, and its main function is to supply water to Dalian city.

The upstream watershed control area of the reservoir is $2085 \mathrm{~km}^{2}$, accounting for $74.1 \%$ of the total watershed area. Biliu River has a humid climate in the northern temperate zone with four distinct seasons, with flood season in June and September, especially in July and August. The average rainfall from 1958 to 2011 above the dam site is $739.4 \mathrm{~mm}$, the average runoff volume per year is 612 million $\mathrm{m}^{3}$, the average sand transfer volume per year is 259,400 tons, and the average temperature per year is $10.6^{\circ} \mathrm{C}$, as shown in Figure 2. The catchment area is dominated by forests and

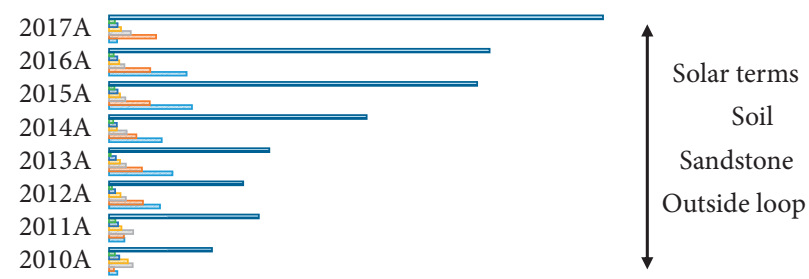

050000100000150000200000250000300000350000 Sandstone,

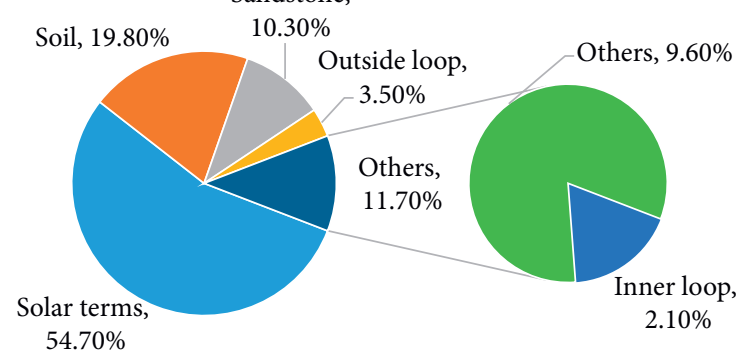

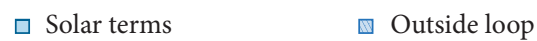

$$
\begin{aligned}
& \text { Q Groundwater } \square \text { Soil } \\
& \text { \Climate } \square \text { Inner loop } \\
& \square \text { Sandstone }
\end{aligned}
$$

Figure 2: Changes in key parameters in the Biliu River basin.

farmland. Since 2010, the impact of solars has become greater and greater, and now it has occupied the absolute position of the factors that have the greatest impact on the climate. It is worth mentioning that since 2012 the impact of sand and rock has been increasing day by day. By 2016, the impact of sand and rock has accounted for more than $20 \%$ of the overall influencing factors, which is the largest influencing factor other than solar. Agriculture is the main industry in this area, and the arable land in the mountainous areas is mostly rain-fed farmland. The upstream tributaries 
of Biliu River completed the Yushi Reservoir in 2001, controlling a watershed area of $313 \mathrm{~km}^{2}$, with a maximum storage capacity of 0.89 billion $\mathrm{m}^{3}$, net regulating water of 0.46 billion $\mathrm{m}^{3}$, mainly to Yingkou city, Spanish mackerel district to provide industrial and urban water supply capacity of $126,000 \mathrm{~m}^{3}$, while also having the function of flood control and irrigation.

2.2. Changes in the Hydrological Elements of the Biliu River. Hydrological elements mainly include rainfall, runoff, temperature, evaporation, and other time series associated with the hydrological cycle. Among them, runoff is the most visible output, which is the direct source of runoff during rainfall. In order to ensure the reliability of the results of the analysis of hydrological elements, refer to the literature containing the study interval 1978-2011 analysis results from 1958-2011, as can be seen in Figure 3; rainfall and runoff are downward trend; the downward trend of runoff is more obvious. In addition to the above-mentioned analysis of parametric uncertainty, it is also worth focusing on the uncertainty of the structure of the model itself. To date, many hydraulic models have been developed in the field of global hydration equipment, and different models have different effects on shutdown simulations at different times and at different levels, under different climate and soil conditions. How does model uncertainty affect off-mode simulation results compared to the impact of model parameter uncertainty on process simulation results?

Hydrological modeling is an important tool for simulating hydrological processes such as runoff and understanding hydrological laws and has important practical significance for the calculation of river basin production and catchment flow, assessment of available water resources, and optimal allocation and dispatch of water resources. However, as the study of hydrological modeling progresses, the uncertainty of hydrological modeling becomes more and more prominent, and the model structure uncertainty and parameter uncertainty have a significant impact on the simulation results. Take the uncertainty of model parameters as an example, hydrological model parameters are often too many and not easy to obtain, and model nonlinearity and parameter correlation may lead to multiple optimal solutions in the model solution space, i.e., the phenomenon of "heteroskedasticity." In recent years, scholars from home and abroad have conducted a lot of studies on the parameter uncertainty of hydrological models. We take the top model as the object of our study and compare the parameter uncertainties between Monte Carlo-based GLUE and Bayesian MCMC in watershed flood simulation and find that the GLUE algorithm can obtain relatively narrow confidence intervals.

The SWAT model is used to simulate daily scale runoff in the Thau watershed in southern France, and the GLUE algorithm is applied to reveal the variation of model parameter uncertainties on the spatial scale, and it is found that regions with the same geographic and climatic conditions are subject to the same uncertainty of model parameters. The uncertainty of parameters is closely related to sensitivity.
Parameter sensitivity analysis helps to deepen the understanding of the effects of different parameters acting individually or together on the model simulation results and is an important direction and essential link in the field of hydrological modeling research. The common methods of parametric sensitivity analysis are local analysis and global analysis. The advantage of global sensitivity analysis is that it cannot only fully consider the effects of different factors on the model output, but also quantify the effects of the interaction between factors on the model output. Nowadays, sensitivity analysis methods based on variance decomposition, such as Sobol method and FAST method, are the hotspots of research in the field of sensitivity analysis. However, it is noteworthy that the above methods are all based on the assumption that the input variables are independent of each other and uncorrelated.

2.3. Basin Water Resources Assessment. Undoubtedly, hydrological models have a high advantage in the assessment of water resources in river basins because of their clear physical meaning and high accuracy of simulation results. However, the model structure is often complex, and the requirements of hydrometeorological data for modeling are high, and the running time is long, which causes some problems in its popularization. The Budyko hypothesis can be divided into two types: parametric and nonparametric. The parametric Budyko model is more flexible than the nonparametric type and is widely used in describing the characteristics of the heat and water balance in a watershed under multiyear average conditions and in quantitatively studying the distribution of rainfall between evaporation and runoff in a watershed.

It proposed a decomposition method based on Budyko's theory to quantitatively assess the influence of climate change and human activities on this variable of runoff and was applied in several fields in the United States. The water availability of oases in the Tarim basin extends the coupled hydrothermal equilibrium relationship based on Budyko assumptions to oases in arid zones; based on Budyko assumptions, coupled global climate models are used to predict future runoff in the Yangtze River basin. In the Budyko model, the parameter $w$ is mostly considered as a reflection of the vegetation cover, soil characteristics, and climate characteristics of the watershed. Admittedly, parameter $w$ is crucial to the Budyko hypothesis and has a significant impact on the application of the curve (e.g., in water resource assessment). Typically, parameter $w$ is estimated by coupling a watershed medium- and long-term water balance model with the Budyko assumptions. The basic assumption of this approach is that the water storage variable in the basin is approximately zero on long-time scales (typically 5-10 years).

Specifically, the parameter $w$ was obtained by solving the functions $w=g(P, R$, and $\mathrm{PE})$ regarding rainfall $(P)$, runoff $(R)$, and potential evaporation (PE). For example, they calculated the parameter $w$ for 64 subbasins of the Yellow River basin based on the multiyear average rainfall, runoff, and potential evaporation of the basin, coupled with the 


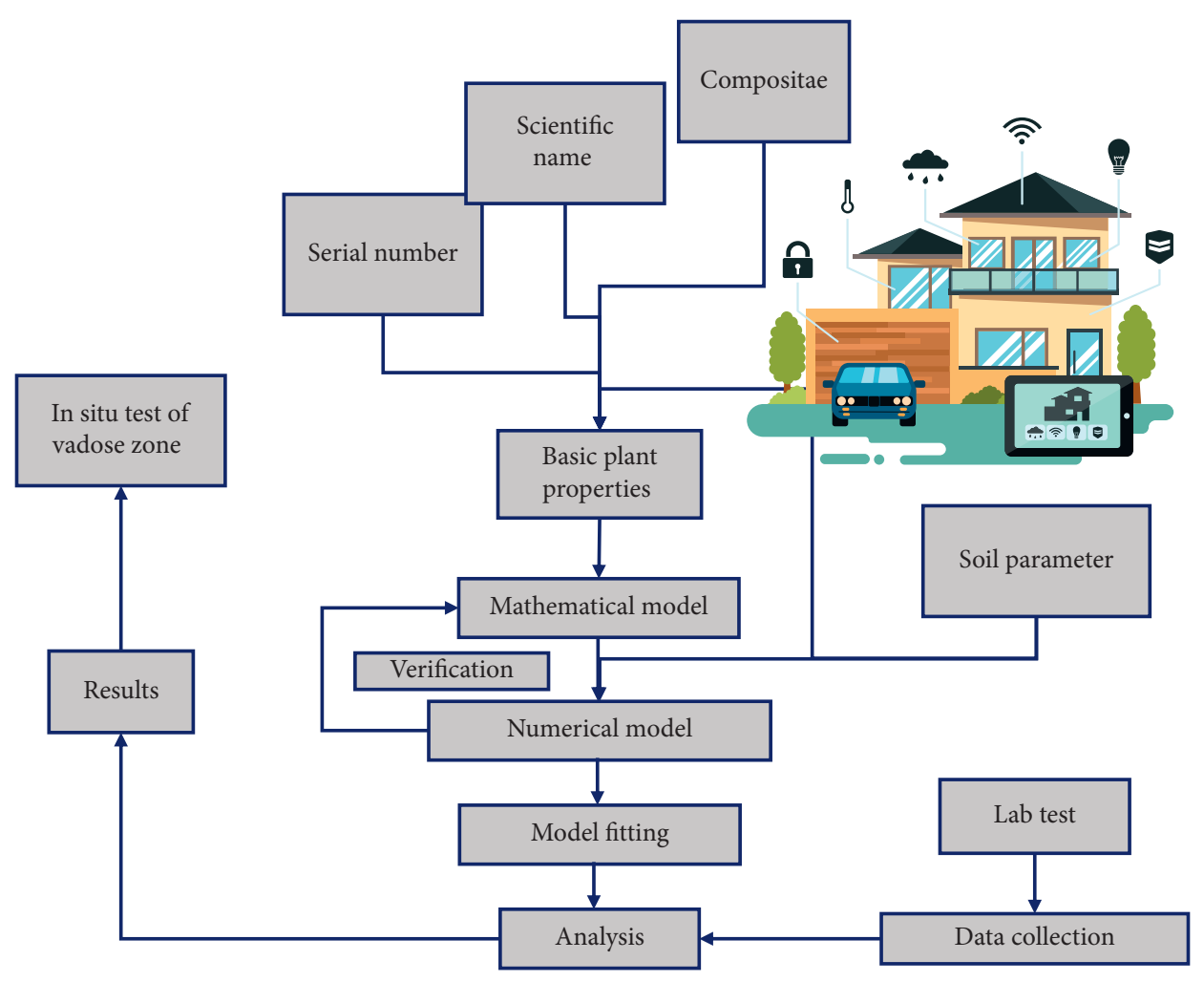

FIgURE 3: Changes in rainfall and runoff.

basin water balance formula and the Budyko model; Pannaraj et al. [12] used the Chaohe River basin as an example to determine the parameters of the Budyko-Fu model using an optimization method. It should be noted that the length of hydrological observations is often limited and contains less information, which makes it difficult to fully characterize the long-term hydrological cycle of the basin. At the same time, most studies also indicate that calculations using limited hydrological data are inevitably accompanied by significant uncertainties. In other words, the uncertainty associated with such limited hydrological data for estimating Budyko's hypothesized parameter $w$ is unquestionable. In practice, ignoring the uncertainty in Budyko's hypothesis $w$ can easily lead to incomplete or even erroneous conclusions. Therefore, it is necessary to investigate the uncertainty in Budyko's assumption and to analyze the impact of this uncertainty in water resources assessment.

\section{SWAT Climate Downscaling Study}

3.1. Watershed SDSM Downscaling Modeling. In this paper, the daily maximum temperature, daily minimum temperature, and daily precipitation of the four stations in the study area are used as the forecast quantities, and the statistical relationships between the three forecast quantities and the forecast factors are established using the NCEP reanalysis data and the 26 nearest forecast factors as the alternative factors. The predictors for each forecast quantity are selected by considering the results of bias correlation analysis and scatter plot simulation and are shown in Figure 4. After selecting the predictors, the Calibrate model of SDSM is used

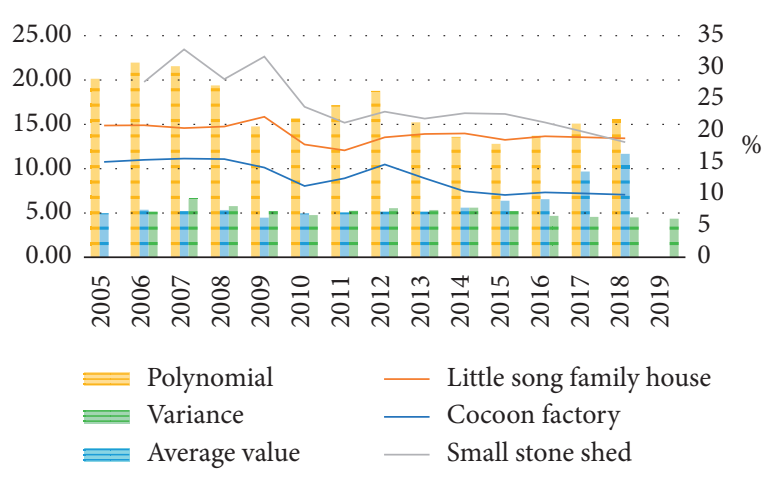

FIgURE 4: Analysis of prognostic factors.

to rate the model. After selecting the predictors, the Calibrate model module is used to rate the model, and the model is used to select the forecast quantity, set the output parameter file and the rate range, select the filtered predictors, and set the conditional or unconditional process type. The model applicability is evaluated using the explained variance ( $R$-squared) and standard error (SE). In this paper, we present the results of the statistical evaluation of the maximum temperature, minimum temperature, and precipitation for the rate period using the rate model for 1961-1990 data.

In the use of statistical downscaling SDSM to obtain scenarios of future weather elements, uncertainty is always present. Similar to the SWAT model, uncertainties may arise from the choice of GCMs, the choice of predictors, and the 
choice of downscaling methods. Among them, the GCMs model, as an important input source of the model, is dominated by the uncertainty, as 26 GCMs models are given in the previous section. The uncertainties arising from the selection of predictors should not be neglected, because there are still many predictors that can be used to predict the quantity on the basis of satisfying the principle of selecting predictors and there are many ways to screen predictors. In addition, the choice of downscaling methods will also lead to uncertainty. For example, different downscaling methods, such as dynamic downscaling and statistical downscaling, have different principles and use different mathematical models, which will inevitably lead to different simulation results and hence uncertainties in the choice of methods.

In this paper, the SDSM model is constructed by selecting the forecast quantity from the meteorological data and the forecast factors from the NCEP and then analyzing the data to determine the forecast factors through bias correlation analysis. The standard error (SE) is evaluated. Then, the maximum temperature, minimum temperature, and precipitation simulation results of the four stations were evaluated and analyzed by comparing the monthly multiyear averages of the measured and simulated values. The results show that the overall model simulation effect is good and the simulation results are reliable and the simulation effect of the same meteorological element differs slightly from site to site. The model can be used to predict the future trend of temperature and precipitation in the Biliu River basin. In addition, it also shows how and why the use of SDSM model brings uncertainty, so that the uncertainty can be taken into account and reduced in subsequent studies.

3.2. Changes in Runoff from Future Climate Scenarios. The maximum temperature, minimum temperature, and precipitation of the Biliu River basin were simulated using the validated SDSM model under two scenarios, RCP4.5 and RCP8.5, in the Can ESM2 model for the periods 2046-2065 and 2081-2100, respectively, and the output of the SDSM model was then compared with the SWAT model coupling. The simulation results of the interannual changes and growth trends of the maximum temperature and minimum temperature show the following: (1) the future temperature (including the maximum temperature and minimum temperature) shows an increasing trend under both scenarios; (2) the increase rate and growth rate of the RCP8.5 scenario are higher than those of the RCP4.5 scenario in the future. Simulations of cumulative interannual precipitation and multiyear average monthly precipitation compared to the base period show the following: (1) precipitation increases to different degrees in the future periods under both scenarios, and the cumulative precipitation in the $2081-2100$ period is higher than that in the 2046-2065 period, but the growth rate in the 2081-2100 period is slightly lower than that in the 2046-2065 period. (2) Precipitation increases in both time periods under both scenarios compared to the base period, and the total annual precipitation is greater in the post2081-2100 time period than in the 2046-2065 time period. Coupled model simulations to obtain runoff for future time periods show that, except for the 2081-2100 time period under the RCP8.5 scenario, runoff decreases under the other three combinations (2046-2065 time period RCP4.5, 2046-2065 time period RCP8.5, and 2081-2100 time period RCP4.5). Other meteorological factors also have a large influence on runoff formation and are to be explored further.

It is the amount of water stored in the polder that determines "when" and "how much" the polder will be drained. The formation of surface runoff in the polder rainfall can be stored in farmland, ponds, ditches, and inland rivers, but the crops in the polder and pond aquaculture usually have certain requirements for water depth; the water in the ditches will also be quickly drained into the river, so the polder water storage role is mainly inland water. In other words, polder drainage measures are mainly based on the storage of water in the river. In the Hirano river network area, the river is a nearly rectangular cross section of the reclaimed land. As a reclaimed settlement of excess water in the reclaimed land, an interconnected river reclaimed land reclaimed at some point through the drainage station outside the reclaimed land. In the actual management of dehydration in the embankment, the manager of the drainage and irrigation station determines whether or not the river is required to drain based on the experience through the water level. Once the water level in the inland river exceeds the warning height, the pump must be turned on to drain until the water level in the inland river returns to a safe height (Figure 5). The warning level and the safety level of the inland river are usually determined by the drainage and irrigation station managers based on experience, although in practice these two water heights are not necessarily exact figures but still can be based on the drainage and irrigation station managers experience to obtain their respective average height. Due to the size of different polders, the inland flow conditions within the polder will vary, so the warning level and the safety level will vary from polder to polder.

3.3. Parameter Sensitivity Analysis and Parameter Rate Setting. The key to the SWAT model's ability of simulating runoff relatively accurately lies in the selection of runoffrelated parameters from the many SWAT models for sensitivity analysis and rate determination. In this paper, 14 parameters were selected from 25 runoff-related parameters to have a greater impact in the region, some of which are as follows: CN2: it means the number of SCS curves at mean humidity; the larger the value, the greater the total runoff; SOL_AWC: the larger the water holding capacity of the field, the smaller the infiltration volume, the shorter the infiltration time; GW_DELAY: it is used to calculate the runoff volume; GW_DELAY: it is used to calculate the runoff volume.

The amount of recharge flowing into the groundwater table each day is related to the depth of the level and the hydraulic characteristics of the seepage zone and the geological composition of the groundwater table; GW_REVAP: the larger the value, the more the reevaporation; when it is equal to 1 , the amount of evaporation is equal to the potential evaporation; $\mathrm{CH}_{-} \mathrm{K} 2$ : the default is 0 ; the larger the 


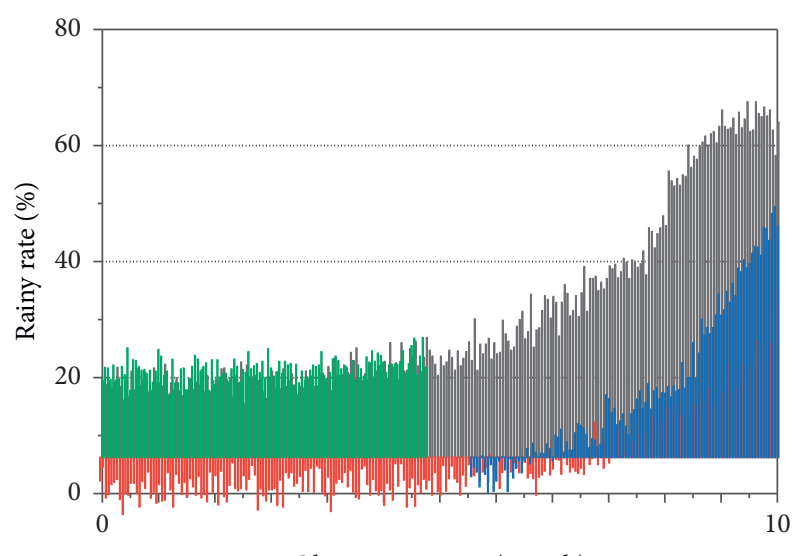

Observation time (month)

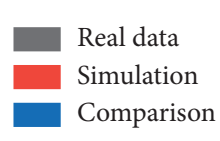

FIGURE 5: Changes in inland water levels.

value, the greater the river transport losses; REVAPMN: it exists only when the water content of the shallow groundwater table exceeds the threshold value aqshthr, rvp; CH_N2: the larger the value, the smaller the flow rate of the convergence; RCHRG_DP: the larger the value, the larger the proportion of recharge water to the deeper groundwater layer; SOL_K: the larger the value, the more the water flowing from the soil layer to the next soil layer, and the more the flow in the soil generated. According to the corresponding modification scheme to set the initial range of parameters, after several iterations to gradually meet the evaluation indicators, we obtained the parameter sensitivity analysis and rate determination results, presenting the final range and best value of the parameters after rate determination, and obtained the sensitivity ranking: $\mathrm{CN} 2, \mathrm{SOL}_{-}-$ AWS, GW_REVAP, GW_REVAP, GWQM, etc. Among them, $\mathrm{CN} 2$ has the highest but significant sensitivity. ALPHA_BF, CANMX, and RCHRG_DP have large $p$ value but small $t$-stat, and SOL_AWS has the second lowest sensitivity.

\section{Results and Discussion}

According to the results of the analysis of rainfall and runoff trends of the Biliu River, the first two years from 1978 to 2011 were used as the warm-up period. In order to make the model simulation results more reliable, the peak years of heavy rainfall, 1994 and 1995, were divided into rate periods; i.e., 1981-1995 was used as the rate period and 1996-2011 was used as the validation period to build the model and obtain the simulation results. The simulation results were evaluated using the three evaluation indicators mentioned above. The simulation results of the monthly values of the model at different periods are shown in Figure 6. Simulation results show that the simulation value and the observed value of the Biliu River hydraulic station are in good agreement with the trend of change, indicating that the flow process is adequately fitted. The result is bad, and the simulation value is generally smaller than the measured value. This may be due to the fact that the effect of snowmelt is not considered. The monthly runoff distribution of the billiards can analyze changes in average monthly runoff from 1981 to 1995 and between 1996 and 2011. The period of abundant water is June to September, and the peak of the runoff reaches August and then begins to decrease, and the dry period is from October to May of the next year. Also, the dry period is simulated better than the rich period, and the rich period is not simulated well during the main flood season, and the peak runoff is the worst in the simulation.

In addition to natural uncertainties, hydrological processes are influenced by a variety of factors, resulting in a wide range of uncertainties. For the hydrological model, which is usually a simplification of the hydrological cycle process in a real basin using a large number of generalized or empirical formulas, the uncertainties in various aspects often interact to influence the uncertainty of the model output. In this paper, the uncertainty results show that the $P$-factor of the rate period is 0.88 and the $R$-factor is 0.61 , which satisfies the criterion that when the $P$-factor $>0.7$ and the $R$-factor $<1$, the uncertainty is smaller and the model simulation is more applicable. The validation period is generally consistent with the rate period, while the slightly higher $P$-factor indicates that $90 \%$ of the observations fall within the uncertainty interval at the $95 \%$ confidence level; the uncertainty of the simulations is relatively smaller. However, as can be seen from Figure 7, the uncertainty interval is larger in the high water period than in the low water period, and the uncertainty is larger in the peak simulation.

The simulation results of the SWAT model in the Biliu River basin: (1) the simulation accuracy, rate setting period, and validation period $\mathrm{R} 2$ are above 0.90 , Ens are above 0.90 , and PBIAS are between plus or minus 5\%; (2) for uncertainty, the $P$-factor and $R$-factor meet the evaluation indexes well, and the uncertainty of the model is small. The SWAT model, based on the previous manual rate setting with fewer parameters, is used to extend the simulation period, and the SUFI-2 automatic rate setting algorithm is used to improve the simulation effect and verify the relatively small uncertainty, which builds a solid foundation for the coupling of climate model and SWAT model. At the same time, it is found that the model is not effective in simulating the peak of the Biliu River and the uncertainty is only a comprehensive consideration, so more factors such as climate change and human activities should be considered in subsequent studies. In addition, due to the limitation of hydrological data, only one hydrological station of the Biliu River is used for the analysis, which is not representative and needs to be further investigated. In other words, polder drainage measures are mainly based on the storage of water in the river. In the plain river network area, the river is nearly rectangular cross section of the polder. Polder of the river mostly interconnected a polder of water storage convergence of excess water in the polder, which can be drained to the polder at some point through the drainage station outside the polder. In the actual management of dewatering in the dike, drainage and irrigation station management personnel is based on experience through the water level to determine 

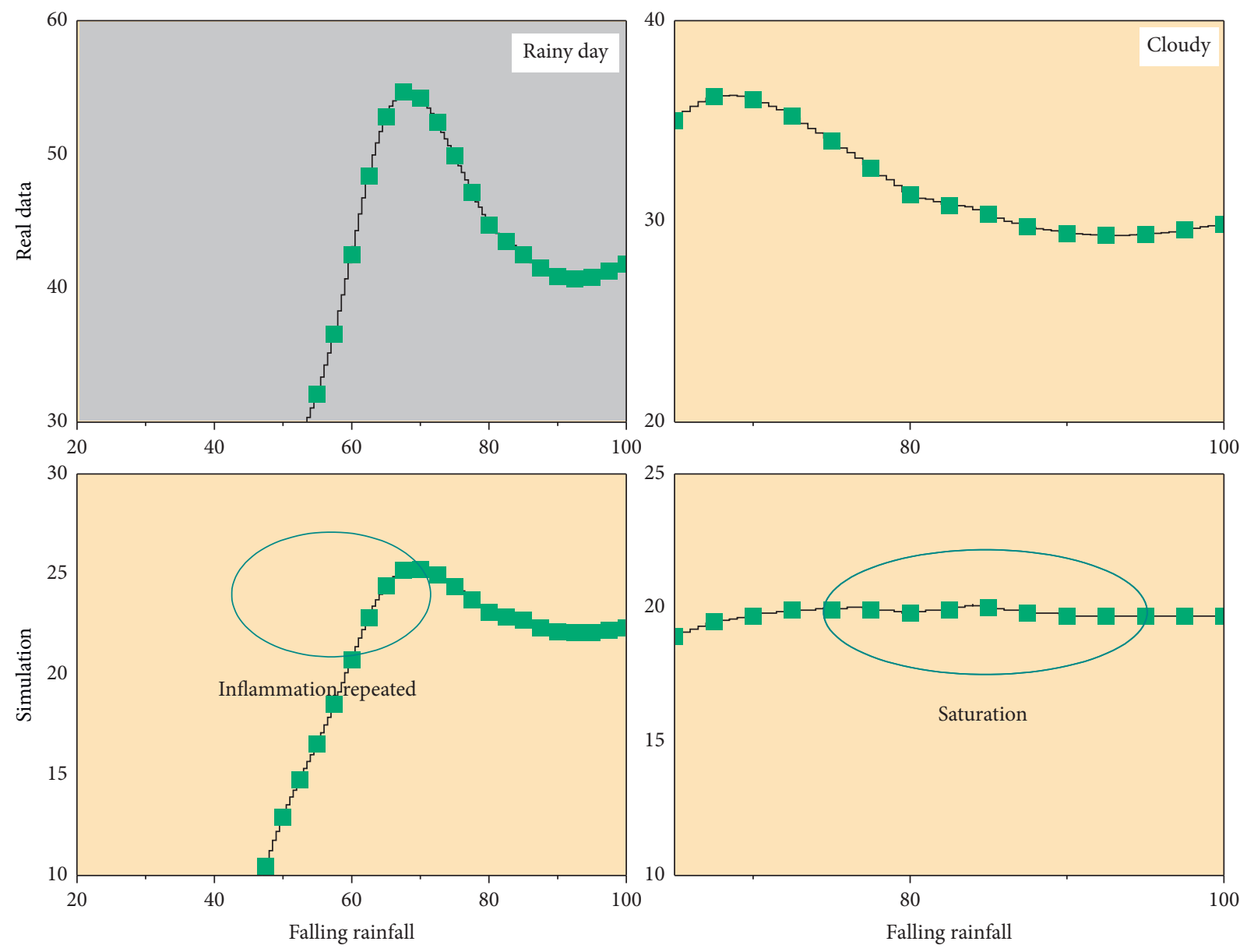

Figure 6: Monthly simulation results.

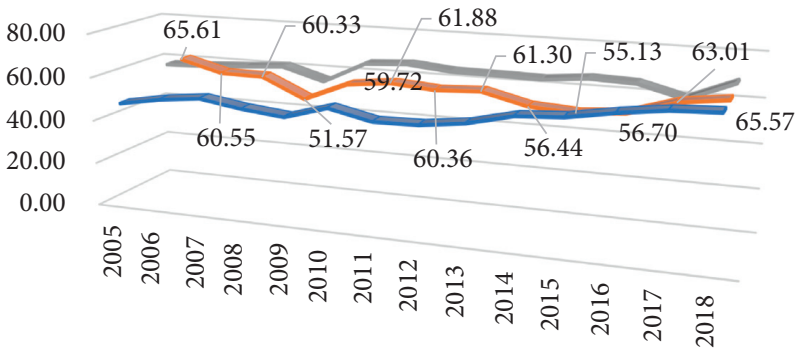

$\square$ Real data

- Simulation

- Comparison

FIGURE 7: Uncertainty in the simulation of the high water period.

the need to drain the river. Once the water level in the inland river exceeds the warning height, the pump must be turned on to drain until the water level in the inland river returns to a safe height. The warning level and the safety level of the inland river are usually determined by the drainage and irrigation station managers based on experience, although in practice these two water heights are not necessarily exact figures but still can be based on the drainage and irrigation station managers experience to obtain their respective average height.

\section{Conclusion}

In this work, we establishe a reservoir planning model that takes into account the impact of several uncertainties and analyses the impact of mixed uncertainties on the reservoir planning and objectives of Xingli on the basis of probability cost theory. The results show that the overall simulation effect is good and the simulation results are reliable and the simulation effect of the same meteorological element varies slightly from one location to another. The model can be used to predict the future trend of temperature and precipitation in the Biliu catchment area. It also shows how and why the use of the model creates uncertainty, so that uncertainty can be taken into account and reduced in later studies. With regard to uncertainties, particular account shall be taken of the uncertainty of the hydrological model parameters and the randomness of precipitation processes, the former having an impact on river flow simulation and the latter having an impact both on river flow simulation and on the water needs of the harvest irrigation. 


\section{Data Availability}

The data used to support the findings of this study are available from the corresponding author upon request.

\section{Conflicts of Interest}

The authors declare that they have no conflicts of interest regarding the work reported in this paper.

\section{Authors' Contributions}

Xiaolong Zhao, Hongyan Wang, and Yongfeng Sun are all staff members of the Yingkou Hydrological Bureau of Liaoning Province, participating in the management of Biliu River. During the completion of the thesis, a large amount of first-hand data came from their field monitoring, and they also participated in the main revision work during the revision of the thesis. They analyzed the influence of mixed uncertainty on reservoir scheduling and Xingli's objectives based on probability box theory. In terms of uncertainties, the uncertainty of hydrological model parameters and the randomness of precipitation processes are mainly considered, with the former having an impact on river runoff simulation and the latter having an impact on both river runoff simulation and crop irrigation water demand.

\section{References}

[1] J. Zhang, J. Chang, J. Ma, C. Zhang, and W. Bao, "Investigation of flame establishment and stabilization mechanism in a kerosene fueled supersonic combustor equipped with a thin strut," Aerospace Science and Technology, vol. 70, pp. 152-160, 2017.

[2] J. Choi, W. Summers, and U. Paszkowski, "Mechanisms underlying establishment of arbuscular mycorrhizal symbioses," Annual Review of Phytopathology, vol. 56, no. 1, pp. 135-160, 2018.

[3] K. Rosario, M. Breitbart, B. Harrach et al., "Revisiting the taxonomy of the family circoviridae: establishment of the genus cyclovirus and removal of the genus gyrovirus," Archives of Virology, vol. 162, no. 5, pp. 1447-1463, 2017.

[4] S. Lee, V. Serpooshan, X. Tong et al., "Contractile force generation by 3D hiPSC-derived cardiac tissues is enhanced by rapid establishment of cellular interconnection in matrix with muscle-mimicking stiffness," Biomaterials, vol. 131, pp. 111-120, 2017.

[5] X. Feng, P. An, X. Li et al., "Spatiotemporal heterogeneity of soil water and salinity after establishment of dense-foliage tamarix chinensis on coastal saline land," Ecological Engineering, vol. 121, pp. 104-113, 2017.

[6] R. Belinchón, P. J. Harrison, L. Mair, G. Várkonyi, and T. Snäll, "Local epiphyte establishment and future metapopulation dynamics in landscapes with different spatiotemporal properties," Ecology, vol. 98, no. 3, pp. 741-750, 2017.

[7] H. Mahmoud and P. Divigalpitiya, "Spatiotemporal variation analysis of urban land expansion in the establishment of new communities in Upper Egypt: a case study of New Asyut city," The Egyptian Journal of Remote Sensing and Space Science, vol. 22, no. 1, pp. 59-66, 2019.
[8] J. Nie, Q. Li, J. Wu et al., "Establishment and validation of a pseudovirus neutralization assay for SARS-CoV-2," Emerging Microbes \& Infections, vol. 9, no. 1, pp. 680-686, 2020.

[9] Y. Liu, L. Yang, W. Zheng, T. Liu, X. Zhang, and J. Liu, “A novel building energy efficiency evaluation index: establishment of calculation model and application," Energy Conversion and Management, vol. 166, pp. 522-533, 2018.

[10] S. Challa, M. Wazid, A. K. Das et al., "Secure signature-based authenticated key establishment scheme for future IoT applications," Ieee Access, vol. 5, pp. 3028-3043, 2017.

[11] M. H. Noe, J. M. Gelfand, J. S. Bryer, S. N. Price, M. A. Judson, and M. Rosenbach, "Responsiveness to change and establishment of the minimal clinically important difference for the cutaneous sarcoidosis activity and morphology instrument," JAMA Dermatology, vol. 156, no. 1, pp. 98-99, 2020.

[12] P. S. Pannaraj, F. Li, C. Cerini et al., "Association between breast milk bacterial communities and establishment and development of the infant gut microbiome," JAMA Pediatrics, vol. 171, no. 7, pp. 647-654, 2017.

[13] H. Yu, "Motivation behind China's "one belt, one road" initiatives and establishment of the asian infrastructure investment bank," Journal of Contemporary China, vol. 26, no. 105, pp. 353-368, 2017.

[14] K. Cure, J.-P. A. Hobbs, T. J. Langlois, D. V. Fairclough, E. C. Thillainath, and E. S. Harvey, "Spatiotemporal patterns of abundance and ecological requirements of a labrid's juveniles reveal conditions for establishment success and range shift capacity," Journal of Experimental Marine Biology and Ecology, vol. 500, pp. 34-45, 2018.

[15] C. Wang, Z. Liu, Z. Chen et al., "The establishment of reference sequence for SARS-CoV-2 and variation analysis," Journal of Medical Virology, vol. 92, no. 6, pp. 667-674, 2020.

[16] F. U. Rutaganira, J. Barks, M. S. Dhason et al., "Inhibition of calcium dependent protein kinase 1 (CDPK1) by pyrazolopyrimidine analogs decreases establishment and reoccurrence of central nervous system disease by Toxoplasma gondii," Journal of Medicinal Chemistry, vol. 60, no. 24, pp. 9976-9989, 2017.

[17] X. Giroud and J. Rauh, "State taxation and the reallocation of business activity: evidence from establishment-level data," Journal of Political Economy, vol. 127, no. 3, pp. 1262-1316, 2019.

[18] S. M. Thomas, G. S. Simmons, and M. P. Daugherty, "Spatiotemporal distribution of an invasive insect in an urban landscape: introduction, establishment and impact," Landscape Ecology, vol. 32, no. 10, pp. 2041-2057, 2017.

[19] Q. N. Li, J. Y. Ma, W. B. Liu et al., "DNA methylation establishment of $\mathrm{CpG}$ islands near maternally imprinted genes on chromosome 7 during mouse oocyte growth," Molecular Reproduction and Development, vol. 87, no. 7, pp. 800-807, 2020.

[20] N. R. Faria, J. Quick, I. M. Claro et al., "Establishment and cryptic transmission of Zika virus in Brazil and the Americas," Nature, vol. 546, no. 7658, pp. 406-410, 2017.

[21] Y. Kitagawa, N. Ohkura, Y. Kidani et al., "Guidance of regulatory $\mathrm{T}$ cell development by Satb1-dependent super-enhancer establishment," Nature Immunology, vol. 18, no. 2, pp. 173-183, 2017.

[22] S. Musah, N. Dimitrakakis, D. M. Camacho, G. M. Church, and D. E. Ingber, "Directed differentiation of human induced pluripotent stem cells into mature kidney podocytes and establishment of a Glomerulus Chip," Nature Protocols, vol. 13, no. 7, pp. 1662-1685, 2018. 
[23] S. Alonso and R. Ruiz-Rufino, "The costs of responsibility for the political establishment of the eurozone (1999-2015)," Party Politics, vol. 26, no. 3, pp. 317-333, 2020.

[24] M. Dorner and D. Harhoff, "A novel technology-industry concordance table based on linked inventor-establishment data," Research Policy, vol. 47, no. 4, pp. 768-781, 2018. 